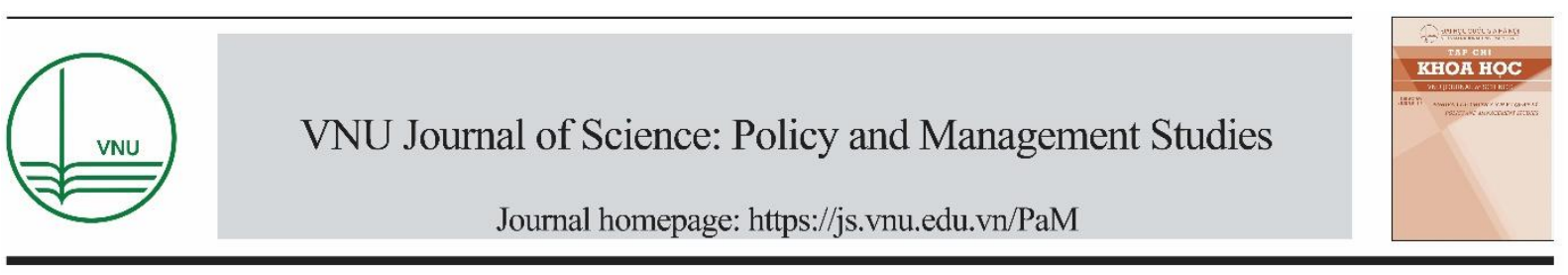

Original Article

\title{
Tourism and Environmental Security in Mekong Delta (Case Study in Can Tho City)
}

\author{
Tran Thi Minh Hoa ${ }^{1, *}$, Chu Khanh Linh ${ }^{2}$ \\ ${ }^{1}$ VNU University of Social Sciences and Humanities, 336 Nguyen Trai, Thanh Xuan, Hanoi, Vietnam \\ ${ }^{2}$ Ho Chi Minh City University of Culture, 51 Quoc Huong, District 2, Ho Chi Minh City, Viet Nam
}

Received 30 October 2020

Revised 31 October 2020; Accepted 2 November 2020

\begin{abstract}
In the master plan on socio-economic development of Vietnam to 2020, with a vision to 2030, the Mekong Delta is identified as a key economic region, a major tourism and service center of the whole country. Several affairs, such as environmental security, the economical use of resources, ecological environment protection, and the social environment, are mentioned and play an important role in the orientation of sustainable socio-economic and tourism development.

Based on the published research results and collected data during the field survey in Can Tho, this discourse will analyze deeply the impacts of tourism on environmental security in Can Tho city. On that basis, the discourse will suggest a number of proposals for other relevant departments in order to develop tourism according to the principles of ensuring environmental security in Can Tho city. Thanks to that, we can draw experience lessons for the whole Mekong Delta.
\end{abstract}

Keywords: Tourism, environmental security, Can Tho city.

\section{Some Theoretical Issues about Environmental Security and Tourism Activities in Vietnam}

Recognizing the importance of ensuring environmental security, on 23 June 2014, the National Assembly of the Socialist Republic of
Vietnam passed the Law on Environmental Protection No. 55/2014/QH13, which explains clearly the concept of environmental security: "Environmental security means to secure not to have a major impact of the environment on the political, social stability and economic development of a country."The Law on

\footnotetext{
${ }^{*}$ Corresponding author.

Email address: hoatm225@yahoo.com
}

https://doi.org/10.25073/2588-1116/vnupam.4273 
Environmental Protection specifies the following:

- The principles of environmental protection,

- Encouraged environmental activities, environmental protection planning, strategic environmental assessment, environmental impact assessment, and environmental protection plan.

In which, Chapter 5 of the Law has clearly stated the regulations on environmental protection in production and business activities.

The Prime Minister issued Directive No. 18/CT-TTg dated 4 September 2013 on "Strengthening the management of the tourism environment, ensuring security and safety for tourists." Directive 18 clearly analyzed the causes of the decline in the number of international tourists in the period of $2012-2013$ due to many issues in the management of the environment, security, and safety for tourists. Since then, the Government has assigned tasks to direct managerial institutions on the ministry, sector, and locality levels to quickly propose and implement strategies, policies, and operational plans to ensure tourism environmental security [1].

From 2013 to 2019, the Asian Development Bank (ADB) has supported Vietnam's tourism industry with approximately114 million USD in tourism infrastructure development, including solid waste, wastewater management, coastal climate change, border works, infrastructure for the community, building common tourism standards, and clean tourist cities. Currently, the ADB is developing an international partnership strategy to support Vietnam in the period of 2021 - 2025, which will continue to support climate change mitigation and adaptation measures in response to increasing environmental risks that Vietnam has to face. This is an excellent opportunity to improve the environmental situation in Vietnam [2].

However, Vietnam's current environmental security is still heavily affected by industrial zones, traditional craft villages, urban construction projects, resorts, real estate business. Environmental pollution in large urban areas such as Ho Chi Minh City and Hanoi is still at alarming levels [3].

In recent years, the tourism industry has made positive contributions to the socioeconomic development of Vietnam. Local infrastructure develops at a rapid speed, on the one hand, creating favorable conditions for tourists to access more tourist destinations. But on the other hand, it also raises concerns about environmental security. The increase in tourists coming to localities has created impacts such as:

i. Increasing pressure from domestic tourist waste;

ii. The risk of water pollution;

iii. Increased emissions from vehicles pollute the air;

iv. Increased possibility of oil pollution in coastal areas, river basins, lakes, streams;

v. Building infrastructure, accommodation facilities alter the structure of land use;

vi. The risk of land degradation affecting the ecology and reducing biodiversity.

Therefore, if environmental security is not maintained, it can weaken the economy, increase social unrest, and increase poverty for nations.

In the Tourism and Tourism Competitiveness Report 2019 published by the World Economic Forum (WEF), Vietnam's index groups have an environmental sustainability of 121/140. The Ministry of Culture, Sports, and Tourism has analyzed and identified the reasons for the low results on environmental indicators. It is determined that the Government, ministries, branches, and localities should pay attention to the following environmental indicators: "Index of the strictness of environmental regulations; Effect and efficiency of environmental regulations; Sustainability in tourism development; The concentration of dust particles in diameter; Wastewater treatment; Change in forest cover; Road quality; Quality of aviation infrastructure; Government targets for the tourism industry; 
The comprehensiveness of annual tourism information" [4].

\section{Effects of Tourism on Environmental Security in Can Tho City}

Can Tho City and the Mekong Delta have rich tourism potential, which can be developed into many types of tourism such as ecotourism, rural tourism, resort tourism, and cultural tourism associated with festivals. Can Tho City is a bridge connecting tourist routes region, inter-region, and cooperation with neighboring countries in the region. As the center of the Mekong Delta tourism area, Can Tho is determined to become a notable example in ensuring the security of the tourism environment.

In 2019, with the efforts of all levels, sectors, businesses, and people, Can Tho City has stepped up the implementation of resolutions on socio-economic development tasks. In particular, the tourism industry of the city welcomed over 8.8 million visitors, which is an increase of $4.6 \%$ compared with the equivalent period in 2018. Overnight visitors increased by $13.1 \%$, counting for 3 million arrivals. Of which, international accommodation reached over 409,000 visitors, an increase of $12.4 \%$ in comparison to 2018. The total revenue from tourists reached over 4,435 billion dong, an increase of $17.2 \%$ over the same period in 2018 . It can be said that the tourism industry of Can Tho City has made important contributions to the local socio-economic development.

Over the past years, Can Tho has synchronously implemented policies to develop sustainable tourism, focusing on environmental protection, tourism resources, and landscape protection. In addition, the city has been completing infrastructure, upgrading traffic systems, building public toilets, ensuring security and order at the tourist areas. The tourist attractions management board is supported by the authorities in reducing the situation of street hawking, theft, begging, and so on. The phenomenon of tourists littering indiscriminately tends to be less common than in previous years. Tourists choose environmentally friendly products, have taken many small and practical actions to contribute to the protection of a xanh - sach - đẹp (green - clean - beautiful) tourist environment, security, and safety.

To assess the environmental security situation in Can Tho city, in August and September of 2020, the authors have conducted a preliminary survey of some tourist attractions on the environmental security situation. Thereby, the authors give initial comments on environmental security in Can Tho city. In addition, the authors continue to collect primary data by means of distributing a questionnaire, surveying local communities and tourists in Can Tho city. The content of the questionnaire is tailored to 2 groups of subjects, in which the total number of responses collected includes: 92 responses from the local community and 110 responses from tourists in Can Tho city. The analytical data are statisticized and processed by Google Form software to increase the reliability of the evaluation.

Results of the survey on people's perceptions related to environmental pollution in Can Tho showed that $80.9 \%$ of people surveyed determined that ensuring environmental security in Can Tho city is very important. $18 \%$ said that ensuring environmental security is important. Based on the results, it is apparent that the local community is very interested in ensuring environmental security in Can Tho city (Figure 1).

With the survey contents of assessing the quality of the living environment, $31.5 \%$ of the surveyed people from the local community said that the air has signs of pollution, $31.5 \%$ said that the air quality is good, $19.1 \%$ said that the air is normal, and $18 \%$ said that the air is very good. Through the survey questionnaire, it was suggested that air pollution is brought by vehicle exhaust and road work, which entail smoke and dust (Figure 2). 
89 responses

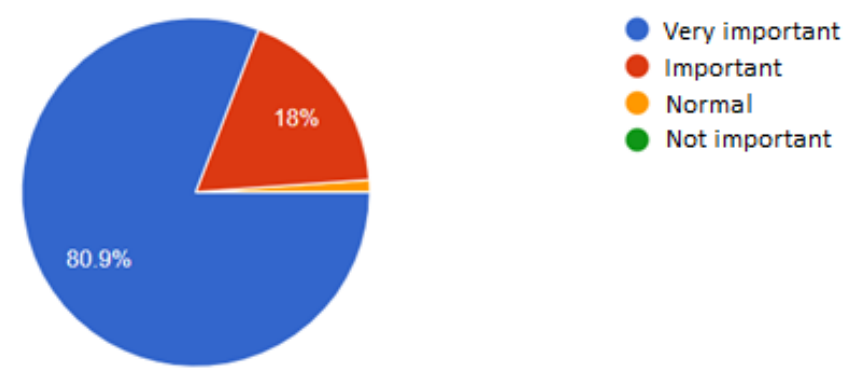

\begin{tabular}{|l|l|}
\hline $80.9 \%$ & Very important \\
\hline $18 \%$ & Important \\
\hline & Normal \\
\hline & Not important \\
\hline
\end{tabular}

Figure 1. Importance of ensuring environmental security in Can Tho city
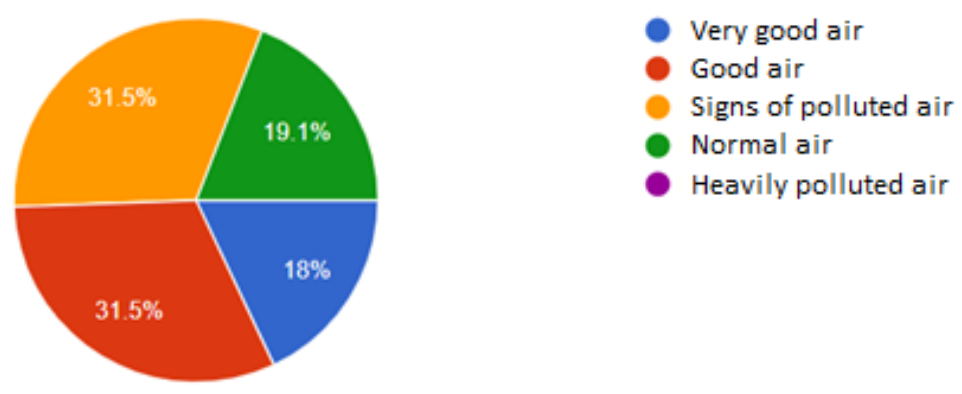

\begin{tabular}{|l|l|}
\hline $18 \%$ & Very good air \\
\hline $31.5 \%$ & Good air \\
\hline $31.5 \%$ & Signs of polluted air \\
\hline $19,1 \%$ & Normal air \\
\hline & Heavily polluted air \\
\hline
\end{tabular}

Figure 2. Assessment of living environment air quality

The increasing number of tourists coming to Can Tho has created many challenges for environmental security in the city. Specifically, $30.1 \%$ of the respondents said that the source of river water pollution in Can Tho is from commercial activities and tourism services (including waste from tourists, rubbish from tourism establishments), $43.8 \%$ of the respondents said that the source of pollution is from domestic waste/toilets on the river, $12.3 \%$ of the respondents said that pollution of river water in Can Tho is from other sources.

In Figures 3 and 4, the authors find that in canals, Can Tho river, Cai Rang floating market, 
Cai Son fruit garden, water pollution has appeared. In which small accommodation businesses, small food and drink businesses along rivers and canals have not been active and enthusiastic in controlling the origin of energy consumption and treating waste. Workers' awareness of environmental protection in business establishments is not high. Garbage and wastewater are discharged directly into rivers by people as well as small processing and manufacturing facilities, causing pollution and loss of beauty. The amount of oil from ships and boats moving on rivers and canals causes severe pollution of river water sources.

\section{3 responses}

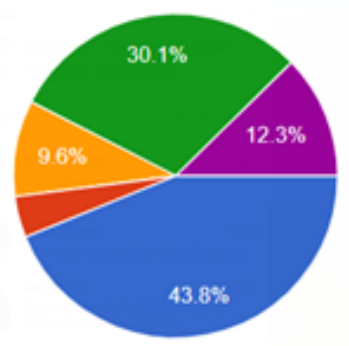

From domestic waste/toilets on the river

- From agricultural production activities

- From industrial production activities

- From commercial activities and tourism services (waste from tourists, waste from tourism businesses)

- Other

\begin{tabular}{|c|l|}
\hline $43.8 \%$ & From domestic waste/toilets on the river \\
\hline $9.6 \%$ & From agricultural production activities \\
\hline $30.1 \%$ & From industrial production activities \\
\hline $12.3 \%$ & $\begin{array}{l}\text { From commercial activities and tourism services (waste } \\
\text { from tourists, waste from tourism businesses) }\end{array}$ \\
\hline & Other \\
\hline
\end{tabular}

Figure 3. Assessment of the source of river water pollution in Can Tho 109 responses
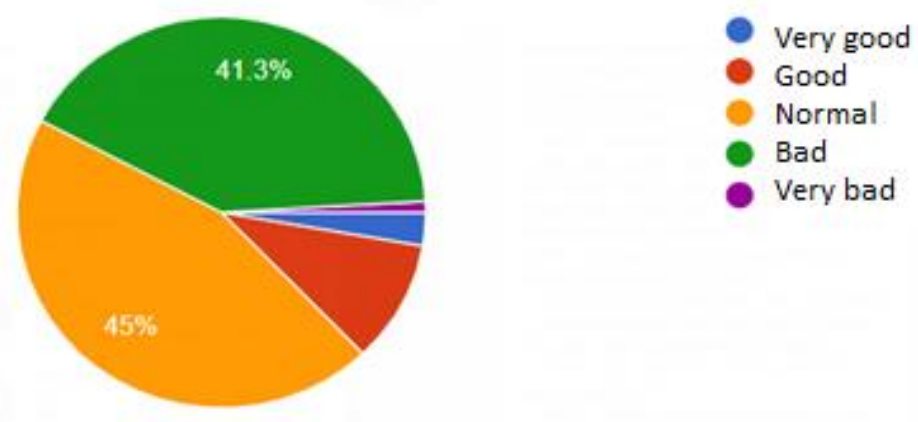

\begin{tabular}{|c|l|}
\hline & Very good \\
\hline & Good \\
\hline $45 \%$ & Normal \\
\hline $41.3 \%$ & Bad \\
\hline & Very bad \\
\hline
\end{tabular}

Figure 4. Visitor comments on river water quality in Cai Rang Floating Market in Can Tho City 
In Figure 5, 69.4\% of the surveys for the local community rated tourism activities have little impact on the environment, $15.3 \%$ of the respondents think that tourism activities have a negative and is one of the most contributing factors to environmental pollution in Can Tho city.

In Figure 6, 53.2\% of tourists rated as having much influence in causing environmental pollution in Can Tho city, whereas $45 \%$ of tourists said that tourism has little effect on causing environmental pollution in Can Tho city.

In Figure 7, visitors commented on social situations such as begging, lottery ticket sales, robbery, jostling, pushing at attractions remain at tourist destinations.

85 responses

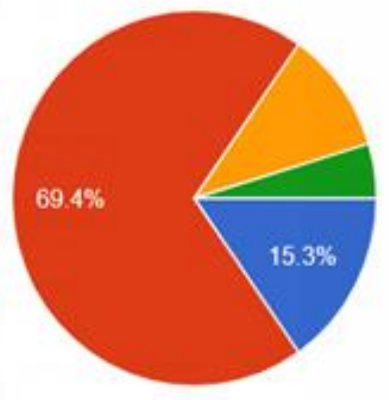

Adversely affecting the environment

Little effect on the environment

No effect on the environment

- Other

\begin{tabular}{|l|l|}
\hline $15.3 \%$ & Adversely affecting the environment \\
\hline $69.4 \%$ & Little effect on the environment \\
\hline & No effect on the environment \\
\hline & Other \\
\hline
\end{tabular}

Figure 5. Assessment of the impact of tourism activities causing environmental pollution in Can Tho city

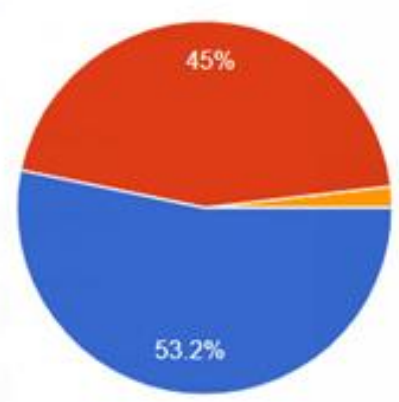

Adversely affecting the environment

- Little effect on the environment

No effect on the environment

\begin{tabular}{|l|l|}
\hline $53.2 \%$ & Adversely affecting the environment \\
\hline $45 \%$ & Little effect on the environment \\
\hline & No effect on the environment \\
\hline
\end{tabular}

Figure 6. Tourists assessed the impact of tourism in causing environmental pollution in Can Tho city 


\section{5 responses}

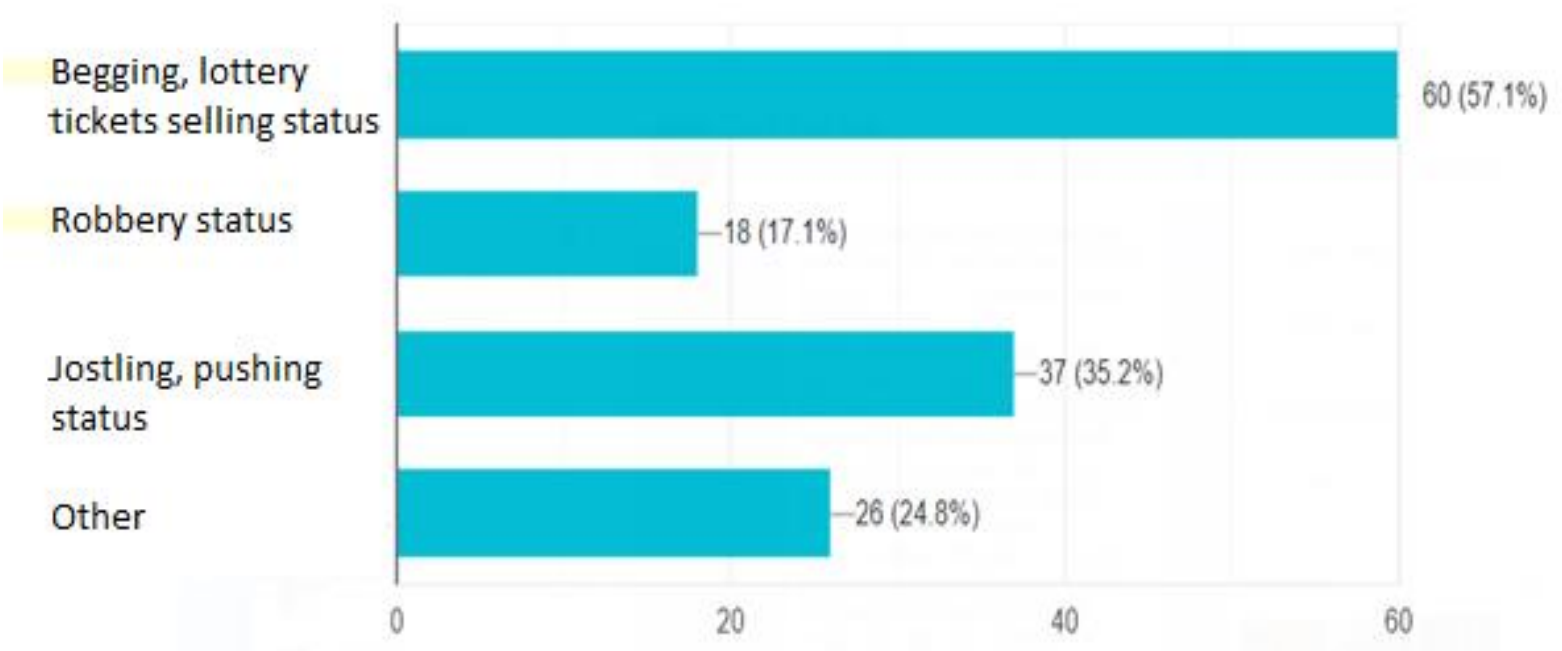

\begin{tabular}{|c|c|}
\hline $57.1 \%$ & Begging, lottery tickets selling status \\
\hline $17.1 \%$ & Robbery status \\
\hline $35.2 \%$ & Jostling, pushing status \\
\hline $24.8 \%$ & Other \\
\hline
\end{tabular}

Figure 7. Tourist comments on social status at tourist destinations in Can Tho city.

Through answering surveys and investigations, tourists perceived that Can Tho city still has not paid attention to measures to treat the polluted environment, the treatment of plastic waste, waste collection, and plastic bags has not been given adequate attention.

One of the reasons for the above situation is that the state management tools on the environment are still limited, the practical application of regulations, decrees, and laws on environmental protection in Can Tho is not yet highly effective, and sanctions against violations have not been fully promoted. Information and communication activities on environmental protection have not been implemented synchronously and widely at all levels, branches, and towards all types of people. Besides, communication activities on television programs introducing local landscape, culture, and history have not been adequately invested in. The rapid development has put tremendous pressure on the responsiveness of natural resources and the environment, entailing pollution and the risk of long-term degradation. All these issues have an impact on the quality of tourism products and the image of Can Tho as a tourist destination. For these reasons, the following proposed solutions to protect tourism environment security in Can Tho city are essential in the current period.

\section{Proposing Solutions to Protect the Tourism Environment Security in Can Tho City}

\section{Macro Solutions}

In order to enhance environmental security protection in tourism activities in Can Tho City, state management agencies at all levels need to have synchronous and practical solutions such as: 
- Developing a strategy and action plan on tourism environment protection in accordance with the development strategy of the tourism industry and the Law on Environmental Protection.

- Completing mechanisms and policies on environmental protection in tourism development. Prioritizing, and synchronously implementing other policies on environmental protection, developing community-based tourism, encouraging green tourism in association with resource conservation, friendly environment to create positive and exemplary changes for the whole region.

- Supplementing regulations on the responsibility of tourism management agencies and specifying the roles and responsibilities of organizations and individuals for environmental protection in tourism in the city. Posting up regulations on environmental protection at relics, relic sites, and tourist sites. Installing and arranging sufficient and reasonable sanitation works and waste collection equipment at tourist attractions.

- Improving the effectiveness of state management on local tourism and communities at tourist sites. Strengthening the management of planning, investment and business in tourism services associated with the protection and exploitation of tourism resources. Strengthening inspection and examination of the observance of legal regulations in tourism activities [5].

- Strengthening close coordination between social order and safety assurance entities at tourist destinations. Resolutely handling negative phenomena such as fraud, price pressure, and theft at destinations. Investing in building a system of signs, signposts, and information points to serve guests.

- Propagating and raising social awareness about the importance of environmental security in the tourism sector.

- Developing training plans and guiding accommodation and food service establishments to carry out activities to raise awareness about environmental security, improving the management of the tourism environment for staff at the attraction.

Setting up a waste collection and treatment system in accordance with regulations; for example, all visitor-transporting vehicles such as boats and canoes must have trash bins. Asking the boat owner and tour guide to remind visitors to protect the environment. Establishing a team to regularly check and give a reasonable penalty framework for each case of causing environmental pollution on the river. Building toilets to serve the needs of the people.

- Collaborating with the Department of Natural Resources and Environment and the Department of Science and Technology to develop technologies using environmentally friendly energy such as solar power and wind power in tourist areas and resorts; to use smart on - off technology in hotel rooms to save electricity; to invest in wastewater treatment systems in tourist sites/area to reuse water sources. Widely applying the waste classification model in tourist sites/area; saving digital information of security violations for the purpose of visitors management; installing cameras at many places where many tourists gather to handle promptly and correct violations in tourism activities.

- Strengthening regional linkages for sustainable tourism development, such as research to find solutions to respond to the impacts of climate change to reduce impacts on life, economy, and tourism of Can Tho city and provinces in the Mekong Delta; formulating policies in the field of environmental protection, orientations for tourism development; linking with tourism businesses to unify the viewpoint of organizing inter-regional tourism routes to minimize impacts on the tourism environment; calling for funds to promote effective environmental protection campaigns; building a system of criteria to ensure environmental security for travel companies and tourism businesses for the Mekong Delta to ensure local characteristics. 


\section{Micro Solutions}

- Tourism businesses need to give priority to develop eco-friendly tourism products or types on the principle of minimizing - recycling reusing natural resources;

- Tourism businesses need to proactively implement solutions to ensure environmental security in their business activities such as: using energy saving methods by recording total energy consumption in a day by department; raising awareness about energy saving through staff training activities; designing instruction boards for use of electrical equipment in hotels; installing space-appropriate lighting devices and adding glasses to catch sunlight and reduce energy in the accommodation; installing automatic air conditioning system and guide tourists to use electrical equipment effectively; using water effectively in swimming pools, watering plants and gardens; reducing waste by utilizing digital technology to store tourist information and conduct other tourism-related activities such as advertisement, reservations, and transactions; committing to treat solid waste in accordance with regulations, reduce waste sources, reuse or recycle wastes [6]; using minimal water and considering the use of renewable energy technologies; ensuring that the staff are knowledgeable about the local environment; encouraging the use of green products to minimize the impact on the environment such as using eco-friendly straws (almond straws, bamboo straws, rice flour straws, paper straws alike) to replace plastic straws.

- Enterprises need to increase communication, education, and propaganda measures about the awareness of protecting the natural and social environment, especially for tourists who are students and young people

\section{Conclusions}

The Vietnam Tourism Development Strategy to 2020 , with a vision to 2030 , has identified the point of view "Sustainable tourism development is closely linked with the preservation and promotion of national cultural values; preserving the landscape, protecting the environment; ensuring security, national defense, social order and safety." [7] Environmental security has played an important role in the socio-economic development of Can Tho city in recent years. With the orientation of developing tourism into a spearhead economic sector, as well as developing Can Tho into a tourist center of the South-Western region, sustainable development is required. State management of tourism environmental security should be focused on. The local tourism management agencies should strengthen the management of security and order, environmental sanitation, culture, and tourism civilization. Economic and tourism development in Can Tho should be closely combined with ensuring social security, ensuring national defense and security, and protecting the ecological environment.

\section{Tài liệu tham khảo}

[1] Prime Minister, Directive No. 18/CT-TTg, Strengthening the management of tourism environment, ensuring security and safety for tourists (In Vietnamese), Hanoi, 4 September 2013.

[2] Asian Development Bank, Member's Summary Information (In Vietnamese), adb.org/sites/default/files/publication/29377/vie2019-vi.pdf, 2020. (accessed 25 August 2020).

[3] L.T.T. Ha, Current Environmental Security In Vietnam (In Vietnamese), tapchitaichinh.vn, http://tapchitaichinh.vn/nghien-cuu-trao-doi/vande-an-ninh-moi-truong-o-viet-nam-hien-nay144583.html, 2018. (accessed 25 August 2020)

[4] T. Ha, Competitiveness of the travel and tourism industry in 2019: Vietnam still lags far behind the top countries in the region (In Vietnamese), Baovanhoa.vn, http://baovanhoa.vn/dulich/artmid/416/articleid/23840/nang-luc-canhtranh-nganh-lu-hanh-va-du-lich-2019-viet-namvan-Top-losers-in-the-region, 2019.

[5] P.T. Luong, Green tourism development with environmental protection and responses to climate change in the Mekong Delta (In Vietnamese), in Workshop "Linking regional green tourism 
development in the Mekong Delta", Can Tho City, 29 June 2015.

[6] T.T. Huong, N.T.B. Hao, N.D. Manh, L.Q. Vinh, N.H. Ha, P.T. Tuyen, T.T. Nga, B.T. Sang, Assessing impacts of ecotourism activities to natural and social environment at Lac village, Chieng Chau commune, Mai Chau district, Hoa Binh province (In Vietnamese), Journal of Forestry Science and Technology, No.1, 2018. http://vnuf.edu.vn/documents/4400543/6788642/1 4.Tran.ThiHuong.pdf

[7] Prime Minister, Decision No. 2473/QD-TTg, Approving the Vietnam Tourism Development Strategy to 2020, with a vision to 2030 (In Vietnamese), Hanoi, 30 December 2011 